\title{
Effect of Protein Supplementation, Fat Globule Size and Storage Time on the Rheological and Sensory Properties of Buffalo Milk Stirred Yogurt
}

\author{
Georgia Dimitreli ${ }^{1}$, Dimitris Petridis ${ }^{1}$, Pantelina Akakiadou ${ }^{1} \&$ Stella Chrysalidou ${ }^{1}$ \\ ${ }^{1}$ Department of Food Technology, Alexander Technological Educational Institute, Thessaloniki, Greece \\ Correspondence: Georgia Dimitreli, Department of Food Technology, Alexander Technological Educational \\ Institute, Thessaloniki, Greece. Tel: 30-231-001-3886. E-mail: dimitrel@food.teithe.gr
}

Received: May 19, 2014 Accepted: June 15, 2014 Online Published: June 21, 2014

doi:10.5539/jfr.v3n5p31 URL: http://dx.doi.org/10.5539/jfr.v3n5p31

\begin{abstract}
In the present study the physicochemical (acidity, color measurements), rheological (viscosity measurements and viscoelastic properties) and sensory (objective and hedonic) properties of stirred yogurt made from buffalo milk were evaluated. Yogurt samples with two fat globule sizes (large: $2.9 \mu \mathrm{m}$; small: $0.87 \mu \mathrm{m}$ ) were prepared with or without the addition of Whey Protein Concentrates (WPC) or Sodium Caseinates (SCN), and stored at $4{ }^{\circ} \mathrm{C}$ for testing at day 1 and 7 after preparation. SCN addition resulted in increased lactic acid concentration, rheological properties (except loss tangent - tan $\delta$ ), white color intensity and sensory viscosity. The effect of WPC on the aforesaid properties was lower when compared to SCN. Small fat globule size also increased the rheological properties apart from tan $\delta$, brightness and sensory viscosity of yogurt samples. Increasing storage time resulted in reduced viscosity, increased acidity and rheological properties apart from $\tan \delta$ and apparent viscosity. The greater decline rates were obvious for Newtonian viscosity at zero shear rate $\left(\eta_{0}\right)$ and instantaneous elasticity $\left(G_{g}\right)$ in yogurts with added SCN and WPC and large globule size and lower or negligible in samples without additives. In contrast, $\tan \delta$ increased at a lower rate when SCN were added in products with large fat globules. Storage time increased the value of flow behavior index (n) in yogurts with large fat globules and, more rapidly, the value of elastic modulus $\left(G^{\prime}\right)$ in the presence of SCN and WPC. The small globule size in the absence of additives produced the lowest response of $b$ and, when WPC was present, the lowest white color intensity. The sensory viscosity reduced the most during storage in yogurt samples with no protein addition.
\end{abstract}

Keywords: buffalo milk, stirred yogurt, milk proteins, fat globule size, storage time, rheological properties, sensory properties

\section{Introduction}

Buffalo milk is ranked second after cow's milk in world milk production at more than $12 \%$ of the total. (Ahmad et al., 2008). Its increased nutritional value - higher protein, fat, calcium and magnesium content but lower cholesterol concentration when compared to other milk species (Agnihotri \& Prasad, 1993; C. D. Khedkar, G. D. Khedkar, Patil, \& Kalyankar, 2003; Park, Juárez, Ramos, \& Haenlein, 2007; Ahmad et al., 2008) - and its various functional properties (higher emulsifying capacity, increased viscosity, etc) makes buffalo milk suitable for the manufacturing of a wide range of dairy products including yogurt (Khedkar et al., 2003).

Yogurt is the most popular fermented milk all over the world. It is produced by the metabolic activity of thermophilic homofermentative lactic acid bacteria that live symbiotically (Streptococcus thermophilus and Lactobacillus delbrueckii subsp. bulgaricus) (Tamine \& Robinson, 2007). The lactic acid production by the starter culture results in a reduction of the net negative charge of casein micelles allowing them to aggregate through hydrophobic and electrostatic bonds that lead to the formation of an acid milk gel (Robinson, Lucey, \& Tamine, 2006). The rheological properties of the final product are governed by many factors including milk composition and pre-treatment (heat treatment, homogenization, etc), fermentation parameters and storage conditions (Sodini, Remeuf, Haddad, \& Corrieu, 2004).

Enrichment of milk with proteins such as Whey Protein Concentrates (WPC) or Sodium Caseinates (SCN) is usually used in yogurt production for texture enhancement and improvement of the gel's water-holding capacity (Lucey, 2004; Tamine \& Robinson, 2007). The nature as well as the proportions of the different proteins (whey 
protein to casein ratio) determine the extent that texture and rheological behavior of the final product can be modified (Remeuf, Mohammed, Sodini, \& Tissier, 2003; Sodini et al., 2004; Amatayakul, Halmos, Sherkat, \& Shah, 2006).

Homogenization is an important pretreatment of the milk for the manufacture of yogurt. Its main impact on yogurt includes increased water-holding capacity, reduced tendency to syneresis and improved texture (increased viscosity or firmness) (Tamine \& Robinson, 2007). Fat globules in homogenized milk may act as a "structure promoter" due to the interactions of membrane caseins with the protein network formed during acidification (Cho, Lucey, \& Singh, 1999) increasing in this way the effective casein concentration (Tamine \& Robinson, 2007). This means that fat globule size is an important factor affecting the extent that homogenization influences yogurt texture.

An important post-fermenting parameter affecting rheological behavior of fermented milks, including yogurt, is storage time. The type of product (set or stirred) and the capacity of the starter to over-acidify or to produce extracellular polysaccharides are closely related to the changes that occur during storage and affect the re-bodying or structure re-formation and thus rheological properties of yogurt (Sodini et al., 2004).

The factors that influence the rheological (Hanif, Zahoor, Iqbal, Ihsan-ul-haq, \& Arif, 2012) and sensory (Masud, Khalid, Maqsood, \& Bilal, 2010; Hanif et al., 2012; Simanca, Andrade, \& Arteage, 2013) properties of buffalo milk yogurt has been the subject of study of a few researchers. Recently Petridis, Dimitreli, Chrysalidou and Akakiadou (2013) evaluated the effect of chemical composition (casein, whey protein and fat content) of buffalo milk on the rheological and sensory properties of stirred yogurt. Authors studied the relative contribution of each one of the three components, as well as the relation between the objective data (instrumental data and trained panelists) and the consumer perception (hedonic response of non-trained panelists). Finally, a consumer-optimized combination of the three components was attempted by the authors in order to create the most marketable product.

The aim of the present work was to study the effect of milk protein addition, fat globule size and storage time on the physicochemical, rheological and sensory properties of stirred yogurt made from buffalo milk. Due to the fact that as a consequence of homogenization a portion of caseins and whey proteins is attached to the fat globule surface, addition of WPC and SCN aimed to reveal possible interactions between the addition of milk proteins and fat globule size. Sensory analysis of the samples was performed so as to relate the sensory with the instrumental perception of texture.

\section{Materials and Methods}

\subsection{Materials}

Fresh raw buffalo milk was purchased from a local dairy farm. A Direct Vat Set (DVS) starter culture consisting of the microorganisms Streptococcus thermophilus and Lactobacillus delbrueckii subsp. bulgaricus (Jointex X3, Dosi 4; CSL Centro Spermentale, de Latte S.P.A, Zelo Buon Persico, Italy) was used for milk inoculation. SCN (MIPRODAN 30; Arla Food Ingredients, Viby J., Denmark) (moisture $\leq 6 \%$; proteins 88\%-93.5\%; fat 1.5\%; ash 4\%; lactose 0.3\%) and WPC (Hellenic Protein S.A., Athens, Greece) (moisture $\leq 5 \%$; proteins 80\%; fat 3.5\%; ash $3 \%$; lactose $10.4 \%$ ) were used as protein supplements.

\subsection{Homogenization of the Milk}

The fresh buffalo milk was heated to $72{ }^{\circ} \mathrm{C}$ for $15 \mathrm{~s}$, cooled rapidly to approximately $30{ }^{\circ} \mathrm{C}$ and homogenized using an ultrasound generator (UP 100H, Ultrasonic Processor Hielscher, Germany). According to Wu, Hulbert, and Mount (2001), high power levels and long exposure time can result in extremely small size fat globules and thus in improved rheological and sensory properties of the final product. Therefore, treatment included application of a power level of $100 \%$ for 30 min or 60 min resulting in large $(2.9 \mu \mathrm{m})$ or small $(0.87 \mu \mathrm{m})$ fat globule size homogenized milk samples. The average diameter of fat globules was determined in milk samples after homogenization using a light scattering apparatus (Mastersizer, 2000, Malvern Instruments Ltd, Marvern, UK). Both fat globule sizes prevented fat globules from rising to the top of the milk to form a distinct layer. According to Tamine and Robinson (2007) the diameter of normal homogenized fat globules ranges from 0.1 to $3.0 \mu \mathrm{m}$. During homogenization the temperature of the milk was maintained at $30{ }^{\circ} \mathrm{C}$.

\subsection{Preparation of Yogurt Samples}

SCN and WPC were added to the milk samples after their homogenization at a concentration of $1.5 \% \mathrm{w} / \mathrm{w}$ and dissolved in a Grant GLS400 shaking water-bath (Grant Instruments Ltd, Cambridge, G.B.) under continuous stirring for $20 \mathrm{~min}$ at $35^{\circ} \mathrm{C}$. The milk with or without the additives was then heated to $85{ }^{\circ} \mathrm{C}$ for $10 \mathrm{~min}$ in the shaking water-bath and cooled down to approximately $42{ }^{\circ} \mathrm{C}$. Following heat treatment, the milk was inoculated 
with the starter culture, according to the instructions of the manufacturer, and incubated (Cooled Incubator Series 8000 , Termaks AS, Bergen, Norway) at $42{ }^{\circ} \mathrm{C}$ until the $\mathrm{pH}$ value reached 4.6. Sterilized glass conical flasks and containers that had a maximum capacity of $1 \mathrm{~L}$ were used for milk treatment and incubation of the samples, respectively. At the end of the fermentation process yogurt samples were treated (cooled and mixed) as described by Petridis et al. (2013). The samples were stored in the refrigerator $\left(4{ }^{\circ} \mathrm{C}\right)$ for a total of seven days before testing (first batch of samples). Six days after the preparation of the first batch, the same process was followed and the new samples (second batch of samples) were stored at $4{ }^{\circ} \mathrm{C}$ for one day before testing. The samples of the first and the second batch were evaluated for sensory and rheological properties at the same day, thereby giving samples with two different storage times. The experimental procedure was conducted in duplicate.

\subsection{Physicochemical Analysis}

Yogurt samples were analyzed for fat content (Gerber method) (ISO, 1976) and lactic acid concentration (\% w/w) (AOAC, 2002). All chemicals used were of analytical grade. The $\mathrm{pH}$ of the samples was determined using a GP353 ATC pH METER (EDT Instruments, Kent U.K.). A tristimulus colorimeter Micro Color LMC (Dr. Bruno Lange GmbH, Dusseldorf, Germany) was used for color measurements, according to the CIE Lab scale. The three color components determined (according to the Hunter Lab format) were L (brightness), a (+ red to -green component) and b (+yellow to - blue component). All measurements were conducted in triplicate.

\subsection{Rheological Measurements}

The rheological behavior of the samples was evaluated as described by Petridis et al. (2013). All rheological measurements were made in triplicate.

\subsubsection{Apparent Viscosity}

The determination of the apparent viscosity was made by placing the samples inside the sample vessel of the custom built pneumatic tube rheometer coded TR-1 Rheometer (A.T.E.I. of Thessaloniki, Greece) (Dimitreli \& Thomareis, 2004) under continuous stirring $(50 \mathrm{rpm})$ at $20^{\circ} \mathrm{C}$. The flow behavior index (n) values were calculated from the flow curves of the samples.

Viscosity measurements were carried out so as to correlate the sensory perception of texture with the rheological properties related to shearing, imitating this way the consumption of stirred yogurt by the consumers.

\subsubsection{Viscoelastic Behavior}

The viscoelastic behavior of the samples was evaluated by applying two small deformation tests, dynamic and creep-recovery test using a DMA rheometer (Bohlin C-VOR 150, Malvern Instruments Ltd, Worcestershire, UK) equipped with a $40 \mathrm{~mm}$ diameter plate and a $4^{\circ}$ stainless steel cone. A Peltier plate system $\left(-30\right.$ to $\left.+180^{\circ} \mathrm{C}\right)$ was used for temperature control. Rheological measurements were performed at $20^{\circ} \mathrm{C}$.

A frequency sweep from 0.01 to $10 \mathrm{~Hz}$ was applied at strain deformation within the linear viscoelastic region $\left(1.304 \times 10^{-5}\right)$ previously determined by an amplitude test, so as to determine the elastic $\left(\mathrm{G}^{\prime}\right)$ and viscous $\left(\mathrm{G}^{\prime \prime}\right)$ moduli as well as the loss tangent $(\tan \delta)$ of the samples. For the statistical analysis of the experimental data, rheological properties at $1 \mathrm{~Hz}$ frequency were used.

A stress of $0.2 \mathrm{~Pa}$ within the linear viscoelastic region (previously determined) was applied to the samples, allowing them to creep, followed by a recovery time that allowed the material to recover partly its initial structure. During these tests the instantaneous and retarded compliance as well as the Newtonian viscosity at zero shear rate $\left(\eta_{0}\right)$ were determined. The creep compliance data were given in the form of elastic moduli data (the reverse of compliance): instantaneous elasticity $\left(\mathrm{G}_{\mathrm{g}}\right)$; retarded elasticity $\left(\mathrm{G}_{\mathrm{R}}\right)$.

\subsection{Sensory Analysis}

Three factors (fixed effects) were examined: protein addition (WPC or SCN), fat globule size and storage time, according to the scheme in Table 1, with each combined level including only two replicates due to highly rising costs to conduct the chosen sensory experiment. For sensory analysis a particular Balanced Incomplete Block sensory design (BIB design, Table 2) was chosen (plain 11.22, Cochran \& Cox, 1957) with the following parameters: $t=13$ treatments, that is the twelve combined levels plus one produced by mixing buffalo and bovine milk in 1:1 proportion without additives and preserved for one day, $\mathrm{k}=4$ treatments per panelist, $\mathrm{b}=13$ panelists, $\mathrm{r}=4$ replicates per treatment and $\lambda=1$ pair of similar treatments in the design. The list of panelists and the order of assessing the treatments per panelist was randomized and three-digit random numbers were stuck on plastic cups. Panelists were hosted in ten sensory booths and to each of them was presented a tray with four yoghurt cups with a specific order for tasting. Yogurt samples (approximately $20 \mathrm{~g}$ ) were equilibrated to $20^{\circ} \mathrm{C}$, gently mixed (by stirring five times), and placed in plastic cups. Bottled water and toast were provided to the panelists to clean their 
palates between samples in both objective and hedonic tests.

Table 1. Three factor experimental design showing 12 coded combined levels

\begin{tabular}{lccc}
\hline \multirow{4}{*}{$1^{\text {th }}$ storage day } & Small fat globule size & large fat globule size \\
& SCN & 1 & 2 \\
& none & 3 & 4 \\
\hline \multirow{2}{*}{$7^{\text {th }}$ storage day } & WPC & 7 & 6 \\
& SCN & 9 & 8 \\
& none & 11 & 10 \\
\hline
\end{tabular}

Abbreviations are as follows, WPC: Whey Proteins Concentrates, SCN: Sodium Caseinates.

Sensory evaluation was based on objective perception of five sensory attributes and was conducted twice. 26 panelists from the staff and research students were selected to participate in the sensory assessment on the basis of frequent consumption of milk products, interest, and availability. The panel members were given a brief initial training using various samples of different product formulations with characteristic texture (for example, very acid and very viscous) every time they were asked to participate in the sensory testing. They were trained to assess the following sensory attributes:

- $\quad$ Odor as the typical aroma of the product ascribed mainly to acetaldehyde

- White color intensity as the brightness

- $\quad$ Acidity as the intensity of the acid flavor in the mouth

- $\quad$ Fattiness as the fatty feeling in the mouth and gum.

- Viscosity as the perceived degree of thickness when yogurt was squeezed between tongue and the roof of the mouth and sheared during the back and forth motions of the tongue.

The unstructured/universal scaling (Munoz \& Civille, 1998) was chosen for the sensory assessment: the panelists were asked to record their evaluation by drawing a vertical line for each sample across a horizontal line $15 \mathrm{~cm}$ long at the point that best reflected their perception of the magnitude of each attribute. The left end $(0 \mathrm{~cm})$ of the line was marked as odorless and not at all white, fatty, sour and viscous. The right end $(15 \mathrm{~cm})$ was marked as high intensity of odor and whiteness and very fatty, sour and viscous.

Table 2. BIB design showing the arrangement of experimental treatments (combined factor levels)

\begin{tabular}{ccccccccccccccc}
\hline Panel / Treat & $1 \mathrm{~A}$ & $2 \mathrm{~A}$ & $3 \mathrm{~A}$ & $4 \mathrm{~A}$ & $5 \mathrm{~A}$ & $6 \mathrm{~A}$ & $1 \mathrm{~B}$ & $2 \mathrm{~B}$ & $3 \mathrm{~B}$ & $4 \mathrm{~B}$ & $5 \mathrm{~B}$ & $6 \mathrm{~B}$ & 13 & $\mathrm{k}$ \\
\hline 1 & 1 & 1 & 0 & 1 & 0 & 0 & 0 & 0 & 0 & 1 & 0 & 0 & 0 & 4 \\
2 & 0 & 1 & 1 & 0 & 1 & 0 & 0 & 0 & 0 & 0 & 1 & 0 & 0 & 4 \\
3 & 0 & 0 & 1 & 1 & 0 & 1 & 0 & 0 & 0 & 0 & 0 & 1 & 0 & 4 \\
4 & 0 & 0 & 0 & 1 & 1 & 0 & 1 & 0 & 0 & 0 & 0 & 0 & 1 & 4 \\
5 & 1 & 0 & 0 & 0 & 1 & 1 & 0 & 1 & 0 & 0 & 0 & 0 & 0 & 4 \\
6 & 0 & 1 & 0 & 0 & 0 & 1 & 1 & 0 & 1 & 0 & 0 & 0 & 0 & 4 \\
7 & 0 & 0 & 1 & 0 & 0 & 0 & 1 & 1 & 0 & 1 & 0 & 0 & 0 & 4 \\
8 & 0 & 0 & 0 & 1 & 0 & 0 & 0 & 1 & 1 & 0 & 1 & 0 & 0 & 4 \\
9 & 0 & 0 & 0 & 0 & 1 & 0 & 0 & 0 & 1 & 1 & 0 & 1 & 0 & 4 \\
10 & 0 & 0 & 0 & 0 & 0 & 1 & 0 & 0 & 0 & 1 & 1 & 0 & 1 & 4 \\
11 & 1 & 0 & 0 & 0 & 0 & 0 & 1 & 0 & 0 & 0 & 1 & 1 & 0 & 4 \\
12 & 0 & 1 & 0 & 0 & 0 & 0 & 0 & 1 & 0 & 0 & 0 & 1 & 1 & 4 \\
13 & 1 & 0 & 1 & 0 & 0 & 0 & 0 & 0 & 1 & 0 & 0 & 0 & 1 & 4 \\
$\mathrm{r}$ & 4 & 4 & 4 & 4 & 4 & 4 & 4 & 4 & 4 & 4 & 4 & 4 & 4 & 52 \\
\hline
\end{tabular}


Treatment coding:

1: whey protein concentrates - small size

2: whey proteins concentrates - large size

3: sodium caseinates - small size

4: sodium caseinates - large size

5: no additives - small size

6: no additives - large size

A: $1^{\text {st }}$ storage day

B: $7^{\text {th }}$ storage day

Treatment 13 was produced by mixing buffalo and bovine milk in 1:1 proportion, without protein addition.

Potential outliers were detected through a dotplot construction between objective sensory scores and treatments. At each treatment, four replicates were checked for remote values from the rest of the aggregated data.

Adjusted sensory mean scores of the variables were calculated from the 13 treatments of each run and the $13^{\text {th }}$ treatment was then removed from further statistical manipulation.

\subsection{Statistical Analysis}

For the statistical analysis a three-way analysis of variance (ANOVA) was performed on three sets of variables: physicochemical, rheological and sensory. Statistically significant effects were considered only when the exact probability level of each test was lower (or equal) than the 0.05 reference level.

A Principal Component Analysis (PCA) was employed to detect potential relationships between attributes of different origin, e.g. sensory and rheological (Sharma, 1996).

All statistical analysis was performed using the Minitab16.0 and CANOCO 5.0 statistical packages.

\section{Results and Discussion}

\subsection{Physicochemical Properties of Yogurt}

According to three-way ANOVA (Table 3), the addition of milk proteins caused the acidity of the samples, expressed as lactic acid concentration, to increase. Specifically, yogurt samples prepared with SCN exhibited the highest values of acidity, followed by the samples prepared with WPC, while samples without protein addition showed the lowest values. Both caseins and whey proteins possess buffering capacity resulting in increased lactic acid concentration at a given $\mathrm{pH}$ value. However, the buffering capacity of caseins is higher when compared to whey proteins (Salaün, Mietton, \& Gaucheron, 2005) resulting in the highest values of acidity. 
Table 3. Mean values of physicochemical variables arranged according to the examined factor levels. Significant effects were extracted from the ANOVA results at 0.05 probability reference level and indicated with different letters in superscripts. Numbers in brackets denote the $95 \%$ confidence intervals of means calculated from the ANOVA's error mean square

\begin{tabular}{|c|c|c|c|c|c|}
\hline & treatment & lactic acid (\%) & $\mathrm{L}$ & $\mathrm{a}$ & $\mathrm{b}$ \\
\hline \multirow{4}{*}{ fat globule size } & \multirow{2}{*}{$\mathrm{S}$} & 1.20 & $92.47^{\mathrm{a}}$ & $2.15^{\mathrm{b}}$ & $4.77^{\mathrm{a}}$ \\
\hline & & $(1.12-12.8)$ & $(92.12-92.81)$ & $(2.35-1.95)$ & $(4.37-5.16)$ \\
\hline & \multirow{2}{*}{$\mathrm{L}$} & 1.20 & $90.97^{b}$ & $2.59 \mathrm{a}$ & $5.03^{\mathrm{b}}$ \\
\hline & & $(1.13-1.28)$ & $(90.40-91.53)$ & $(2.78-2.42)$ & $(4.80-5.27)$ \\
\hline \multirow{6}{*}{ additives } & \multirow{2}{*}{ WPC } & $1.22^{\mathrm{b}}$ & 91.65 & $2.40^{\mathrm{ab}}$ & $5.53^{b}$ \\
\hline & & $(1.13-1.32)$ & $(90.46-92.84)$ & $(2.52-2.28)$ & $(5.43-5.62)$ \\
\hline & \multirow{2}{*}{$\mathrm{SCN}$} & $1.27^{\mathrm{c}}$ & 92.23 & $2.13^{\mathrm{bc}}$ & $4.68^{\mathrm{a}}$ \\
\hline & & $(1.19-1.35)$ & $(91.77-92.68)$ & $(2.43-1.82)$ & $(4.56-4.79)$ \\
\hline & \multirow{2}{*}{ none } & $1.11^{\mathrm{a}}$ & 91.28 & $2.59^{\mathrm{a}}$ & $4.50^{\mathrm{a}}$ \\
\hline & & $(1.03-1.20)$ & $(90.54-92.01)$ & $(2.93-2.25)$ & $(4.17-4.83)$ \\
\hline \multirow{4}{*}{ storage day } & \multirow{2}{*}{1} & $1.11^{\mathrm{a}}$ & 91.76 & 2.38 & 4.90 \\
\hline & & $(1.06-1.15)$ & $(91.12-92.40)$ & $(2.63-2.12)$ & $(4.56-5.24)$ \\
\hline & \multirow{2}{*}{7} & $1.30^{\mathrm{b}}$ & 91.68 & 2.37 & 4.90 \\
\hline & & $(1.26-1.34)$ & $(90.96-92.39)$ & $(2.59-2.14)$ & $(4.57-5.24)$ \\
\hline
\end{tabular}

The values of variable a are all negative.

WPC: Whey Proteins Concentrates, SCN: Sodium Caseinates, S: Small fat globule size, L: Large fat globule size, and finally $\mathrm{L}$, $\mathrm{a}$ and $\mathrm{b}$ are the three components of color.

The lactic acid concentration of yogurt samples increased during storage (Table 3). This can be attributed to the metabolic activity of the bacteria that ferment lactose to give lactic acid, even at low temperatures (Walstra, Wouters, \& Geurts, 2006). Amatayakul et al. (2006) also reported an increase in lactic acid concentration of yogurt samples, prepared with exopolysaccharide-producing starter cultures (capsular or ropy) and various casein to whey protein ratios, during storage.

Yogurt samples with small fat globule size exhibited higher values for the color components $\mathrm{L}$ and a but lower for the $b$ component when compared to the samples having large fat globule size (Table 3). The white color of yogurt samples is caused by the light scattering of fat globules and casein micelles (Walstra et al., 2006), while riboflavin is responsible for the green (negative values of a component) and the yellow (positive values of $b$ component) color intensity of the samples. Riboflavin is a yellow-green fluorescent compound of milk (Fox \& McSweeney, 1998). The increase in brightness (L) (white color intensity) at yogurt samples with decreasing fat globule size is due to the increased fat surface area causing the reflection of the light to increase. The decrease in green and yellow color intensity with decreasing fat globule size can be attributed to the increased reflection of light reducing the impact of riboflavin.

The $\mathrm{b}$ color component (yellow color intensity) exhibited higher values in yogurt samples prepared with WPC (Table 3). This is due to the presence of riboflavin in WPC that results in a yellowish color in the samples (Walstra et al., 2006). The a component of color is highest when SCN and WPC are present. The decrease in green color intensity with milk protein addition can be also attributed to the increased reflection of light due the presence of caseins and denatured whey proteins. Increasing the casein content of the system causes the reflection of the light to increase, presumably due to casein aggregation which increases the number and size of scattering particles. Denaturation of whey proteins during heat treatment of the milk allows them to form complexes with the caseins and whey proteins of the serum as well as of those embedded in fat globule membranes (Lucey, Munro, \& Singh, 1998), thereby increasing the size of serum protein aggregates and the hydrodynamic volume of the fat, both of which result in increased reflection of light.

\subsection{Rheological Properties of Yogurt}

The three-way ANOVA revealed that the decrease in fat globule size caused the response of the rheological attributes to increase and the effect of $\tan \delta$ to decrease (Table 4). The homogenized fat globules are embedded in the protein matrix through the interaction of the fat globule membrane proteins with the proteins of the serum. 
The smaller the size of the fat globules, the bigger their surface and the more proteins (mainly caseins) from the serum attached to the fat globule surface. As a result the number of structure-building components in the system is increased (Robinson et al., 2006) and the fat globules act as "structure promoter" as they participate in the formation of the protein network, increasing the strength of the matrix. In such a system the number of elastic bonds is increased resulting in increased viscoelastic properties but reduced viscous behavior (decreased values of $\tan \delta$ ). Furthermore, due to the increased hydrodynamic volume of the fat the resistance to flow is increased resulting in increased values of apparent viscosity (Figure 1). The increase in flow behavior index values can be attributed to the small size of fat globules, caused by milk homogenization. This results in smaller in size and less flexible particles, and a tendency towards Newtonian behavior.

Table 4. Mean values of rheological attributes arranged according to the factor levels. Significant effects were extracted from the ANOVA results at 0.05 probability reference level and indicated with different letters in superscripts. Numbers in brackets denote the $95 \%$ confidence intervals of means calculated from the ANOVA's error mean square

\begin{tabular}{|c|c|c|c|c|c|c|c|}
\hline & treatment & $\mathbf{n}$ & $\mathrm{G}^{\prime}(\mathrm{Pa})$ & $\tan \delta$ & $\eta_{0}(\operatorname{Pa} \times s)$ & $\mathrm{G}_{\mathrm{R}}(\mathrm{Pa})$ & $\mathbf{G}_{\mathrm{g}}(\mathbf{P a})$ \\
\hline \multirow{4}{*}{$\begin{array}{c}\text { fat globule } \\
\text { size }\end{array}$} & \multirow{2}{*}{$\mathbf{T}$} & $0.874^{\mathrm{b}}$ & $705.6^{\mathrm{b}}$ & $0.754^{\mathrm{a}}$ & $180642^{b}$ & $877.6^{\mathrm{b}}$ & $1917.3^{b}$ \\
\hline & & $(0.805-0.943)$ & $(627.5-783.6)$ & $(0.742-0.767)$ & $(133211-228074)$ & $(675.8-1099.4)$ & $(1532.2-2302.5)$ \\
\hline & \multirow{2}{*}{$\mathbf{L}$} & $0.765^{\mathrm{a}}$ & $298.4^{\mathrm{a}}$ & $0.918^{\mathrm{b}}$ & $66211^{\mathrm{a}}$ & $662.6^{\mathrm{a}}$ & $1024.8^{\mathrm{a}}$ \\
\hline & & $(0.738-0.791)$ & $(244.3-352.5)$ & $(0.866-0.971)$ & $(37243-95179)$ & $(452.0-873.2)$ & $(806.6-1243.0)$ \\
\hline \multirow{6}{*}{ additives } & \multirow{2}{*}{ WPC } & $0.857^{\mathrm{b}}$ & $467.1^{\mathrm{c}}$ & $0.854^{\mathrm{c}}$ & $99316^{\mathrm{c}}$ & $386.6^{\mathrm{a}}$ & $890.1^{\mathrm{a}}$ \\
\hline & & $(0.770-0.944)$ & $(279.3-654.9)$ & $(0.770-0.937)$ & (45632-152999) & $(272.5-500.7)$ & $(600.2-1180.0)$ \\
\hline & \multirow{2}{*}{ SCN } & $0.869^{b}$ & $630.9^{\mathrm{b}}$ & $0.775^{\mathrm{a}}$ & $202135^{\mathrm{b}}$ & $1142.6^{\mathrm{b}}$ & $1973.6^{\mathrm{b}}$ \\
\hline & & $(0.799-0.939)$ & $(428.2-833.5)$ & $(0.739-0.811)$ & $(135399-268871)$ & $(1040.0-1245.1)$ & $(1387.5-2559.7)$ \\
\hline & \multirow{2}{*}{ none } & $0.732^{\mathrm{a}}$ & $408.0^{\mathrm{a}}$ & $0.880^{\mathrm{b}}$ & $68830^{\mathrm{a}}$ & $781.0^{\mathrm{c}}$ & $1549.6^{\mathrm{c}}$ \\
\hline & & $(0.714-0.749)$ & $(246.1-569.9)$ & $(0.776-0.984)$ & (35375-102285) & $(696.2-865.9)$ & $(1223.3-1875.8)$ \\
\hline \multirow{4}{*}{ storage day } & & $0.803^{\mathrm{a}}$ & $475.7^{\mathrm{a}}$ & $0.846^{\mathrm{b}}$ & 123977 & $747.8^{\mathrm{a}}$ & $1448.7^{\mathrm{a}}$ \\
\hline & & $(0.733-0.873)$ & $(330.3-621.0)$ & $(0.775-0.917)$ & $(68113-179842)$ & $(530.1-965.4)$ & $(1005.1-1892.2)$ \\
\hline & & $0.835^{\mathrm{b}}$ & $528.3^{\mathrm{b}}$ & $0.827^{\mathrm{a}}$ & 122876 & $792.4^{\mathrm{b}}$ & $1493.5^{\mathrm{b}}$ \\
\hline & & $(0.781-0.890)$ & $(374.1-682.5)$ & $(0.766-0.887)$ & $(69480-176273)$ & $(574.6-1010.2)$ & $(1076.2-1910.8)$ \\
\hline
\end{tabular}

WPC: Whey Proteins Concentrates, SCN: Sodium Caseinates, S: Small fat globule size, L: Large fat globule size, n: Flow behavior index, $G^{\prime}$ : Elastic modulus, $G_{g}$ : instantaneous elasticity, $G_{R}$ : retarded elasticity, $\eta_{0}$ : Newtonian viscosity.

The same view is also discernible for the SCN addition after which maximum values were achieved (Table 4). Increasing the casein content of the samples resulted in increased number of protein bonds, a more dense protein matrix and thus increased viscoelastic properties and reduced viscous behavior (decreased values of $\tan \delta$ ). Simultaneously, the increased hydrodynamic volume of the formed aggregates was the cause for the increased values of apparent viscosity (Figure 1). These findings are in good agreement with our previously published results (Petridis et al., 2013).

As it can be seen in Table 4, WPC addition mediated the response of $\mathrm{G}^{\prime}$, $\tan \delta$ and $\eta_{0}$ and reduced the effects of $\mathrm{G}_{\mathrm{R}}$ and $\mathrm{G}_{\mathrm{g}}$, while according to Figure 1 they also mediated the apparent viscosity. The pronounced effect of SCN when compared to WPC might be attributed to the existence of caseins in complexes (micelles) that have increased hydrodynamic volume and size, and to the partition of caseins into the fat globule membrane as a consequence of homogenization. Casein adsorption onto the membrane favors aggregation of fat globules during 
milk acidification, as the isoelectric point of caseins is approached, and their incorporation into the gel network (Sodini et al., 2004). The cross-linking or bridging of whey proteins with caseins or other denatured whey proteins during heat treatment of the milk (Lucey et al., 1998) is responsible for the increased elastic character of the samples prepared with WPC when compared to samples prepared without protein addition. The lowest values of $G_{R}$ and $G_{g}$ that exhibited the samples made with WPC might be attributed to the increased water holding capacity of whey proteins. Probably water molecules interfere between protein molecules after the application of the shear stress and the breakdown of the bonds of the protein matrix, preventing the reformation of bonds during relaxation. In the absence of proteins, $n, G^{\prime}$ and $\eta_{0}$ were recorded at low values, $G_{R}$ and $G_{g}$ at intermediate values and $\tan \delta$ at highest response (Table 4).

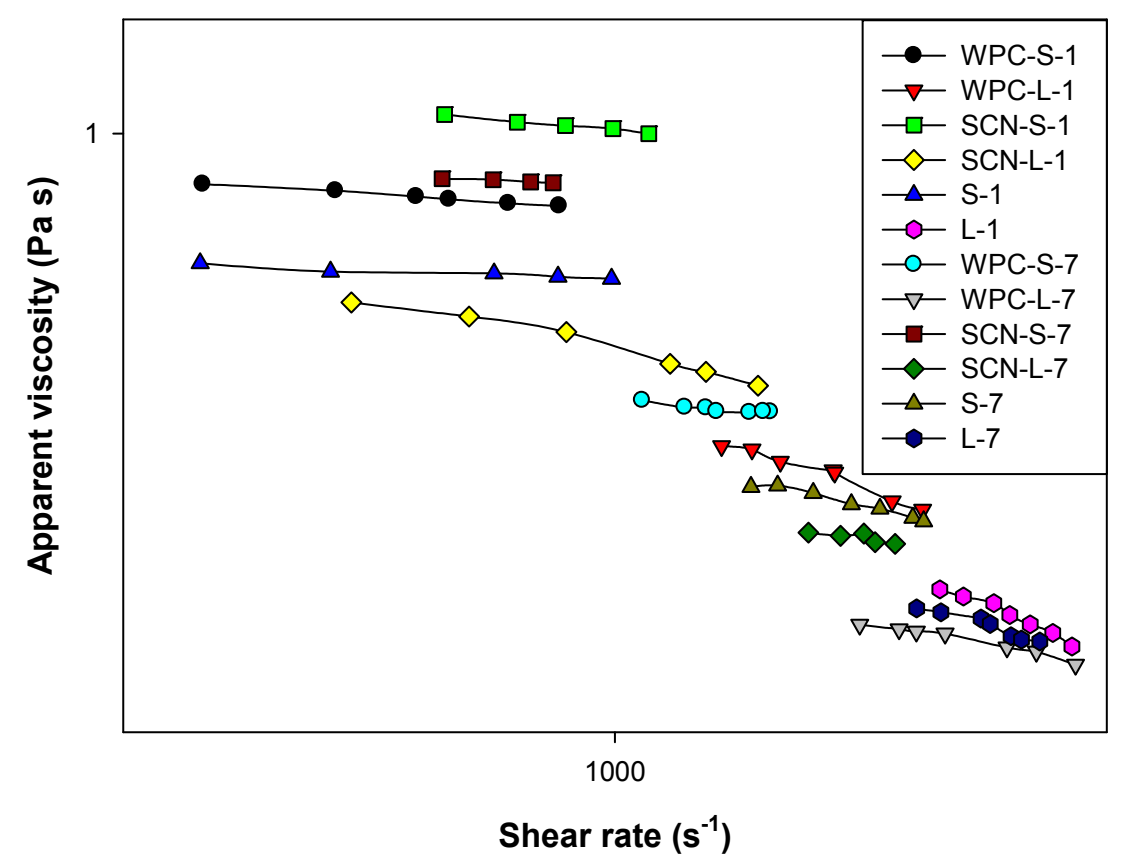

Figure 1. The flow curves of the yogurt samples. Abbreviations are as follows, WPC: Whey Proteins Concentrates, SCN: Sodium Caseinates, S: Small fat globule size, L: Large fat globule size, 1: 1 day of storage, 7: 7 days of storage

Storage for one week considerably increased the values of the rheological variables apart from $\tan \delta$ which peaks the first day (Table 4). Increase in $G^{\prime}$ with simultaneous decrease in $\tan \delta$ values during storage was reported by Serra, Trujillo, Guamis and Ferragut (2009) for stirred yogurt samples made from ultra-high pressure homogenization-treated milk. This can be attributed to the re-formation of (weak) bonds in the stirred yogurt during storage (Lee \& Lucey, 2006). Stirred yogurt can be considered as a concentrated dispersion of gel aggregates formed during shearing of the gel after fermentation. These aggregates undergo considerable rearrangement and new protein bonds are formed depending of the number and availability of the charged groups. The new bonds contribute to increased elasticity of yogurt samples. On the contrary, as it can be seen in Figure 1, the increase in storage time caused the apparent viscosity of the samples to decrease. This behavior may be related to to the increased fat content of buffalo milk and the subsequently larger number of fat globules. Under high shear rates, these fat globules may force apart and break the newly formed weak interactions, reducing in this way the size of the aggregates and resulting eventually in reduced resistance to flow and thus reduced apparent viscosity. Smaller aggregates can rotate and orientate themselves more easily to the direction of flow, showing a tendency towards Newtonian behavior. This hypothesis is strengthened by the dependence of $\mathrm{n}$ by the interaction between fat globules and storage time, which is discussed in section 3.4.

\subsection{Sensory Properties of Yogurt}

Yogurt samples with WPC addition exhibited lower values for the sensory intensity of white color when compared to samples prepared with SCN or without protein addition (Table 5). This is due to the presence of 
riboflavin into the WPC and to the yellowish color that imparts to the samples (Walstra et al., 2006) and is in a good agreement with the results from the physicochemical analysis.

Table 5. Mean values of objective sensory attributes arranged according to the factor levels. Significant effects were extracted from the ANOVA results at 0.05 probability reference level and indicated with different letters in superscripts. Numbers in brackets denote the $95 \%$ confidence intervals of means calculated from the ANOVA's error mean square

\begin{tabular}{|c|c|c|c|c|c|c|}
\hline & treatment & ODOUR & COLOR & ACIDITY & FATTINESS & VISCOCITY \\
\hline \multirow{4}{*}{$\begin{array}{c}\text { fat globule } \\
\text { size }\end{array}$} & \multirow{2}{*}{ S } & 7.6 & 10.3 & 7.6 & $9.9^{\mathrm{b}}$ & $11.0^{\mathrm{b}}$ \\
\hline & & $(6.5-8.7)$ & $(8.9-11.7)$ & $(5.8-9.3)$ & $(9.2-10.6)$ & $(9.6-10.4)$ \\
\hline & \multirow{2}{*}{$\mathrm{L}$} & 7.3 & 9.3 & 8.8 & $8.7^{\mathrm{a}}$ & $8.3^{\mathrm{a}}$ \\
\hline & & $(6.6-8.1)$ & $(8.6-10.0)$ & $(7.0-10.5)$ & $(8.1-9.3)$ & $(7.0-9.6)$ \\
\hline \multirow{6}{*}{ additives } & \multirow{2}{*}{ WPC } & 8.0 & $8.4^{\mathrm{a}}$ & 7.9 & 9.9 & $8.3^{\mathrm{a}}$ \\
\hline & & $(7.1-8.9)$ & $(7.1-9.6)$ & $(5.7-10.2)$ & $(8.7-11.1)$ & $(6.9-9.8)$ \\
\hline & \multirow{2}{*}{$\mathrm{SCN}$} & 7.7 & $10.8^{\mathrm{b}}$ & 8.5 & 9.0 & $12.1^{\mathrm{b}}$ \\
\hline & & $(6.8-8.2)$ & $(9.7-11.8)$ & $(6.3-10.7)$ & $(8.2-9.9)$ & $(11.0-13.3)$ \\
\hline & \multirow{2}{*}{ none } & 6.6 & $10.2^{\mathrm{b}}$ & 8.0 & 8.9 & $8.6^{\mathrm{a}}$ \\
\hline & & $(5.1-8.2)$ & $(8.9-11.5)$ & $(5.3-10.7)$ & $(8.2-9.6)$ & $(6.7-10.4)$ \\
\hline \multirow{4}{*}{ storage day } & \multirow{2}{*}{1} & 7.1 & 9.5 & $6.0^{\mathrm{a}}$ & 9.6 & $10.4^{\mathrm{b}}$ \\
\hline & & $(6.2-8.1)$ & $(8.3-10.7)$ & $(4.9-7.1)$ & $(9.0-10.3)$ & $(9.0-11.9)$ \\
\hline & \multirow{2}{*}{7} & 7.8 & 10.1 & $10.3^{\mathrm{b}}$ & 8.9 & $8.9^{\mathrm{a}}$ \\
\hline & & $(6.8-8.8)$ & $(9.1-11.1)$ & $(9.2-11.4)$ & $(8.2-9.7)$ & $(7.3-10.6)$ \\
\hline
\end{tabular}

WPC: Whey Proteins Concentrates, SCN: Sodium Caseinates, S: Small fat globule size, L: Large fat globule size.

The acidity of the samples increased with increasing storage time (Table 5) due to the metabolic activity of bacteria (Walstra et al., 2006), in accordance with the variation of their lactic acid concentration.

Fattiness in yogurts with small fat globules size exhibited higher values when compared to yogurts prepared with large fat globule size (Table 5). This effect can probably be attributed to the increased hydrodynamic volume of the fat with decreasing fat globule size resulting in increased mouth-feeling of fattiness.

According to the sensory analysis, SCN addition and small fat globule size caused the viscosity of the samples to increase (Table 5), which is in a good agreement with the rheological evaluation of the samples (Table 4, Figure 1). The increased hydrodynamic volume of the formed aggregates and the fat, respectively, are the cause for the increased values of viscosity.

The increase in storage time resulted in a reduction of the sensory viscosity of the samples, which is in accordance with the results from the determination of the apparent viscosity of yogurt. Panelists were able to distinguish a viscosity decrease with increasing time and strengthened the results from the large deformation test. During storage, buffalo yogurt samples exhibited different rheological behavior under the application of stress or strain within the linear viscoelastic region when compared to high shear rates. This behavior as has already been discussed in section 3.2 may be related to the increased fat content of buffalo milk.

\subsection{Interactions}

Statistically significant interactions have been recorded at particular factor combinations. In particular, greater decline rates were obvious for attributes $\eta_{0}$ and $\mathrm{G}_{\mathrm{g}}$ in yoghurts with added SCN and WPC and with large globule size and lower or negligible in samples without additives (Figure 2). The increase in $\eta_{0}$ and $\mathrm{G}_{\mathrm{g}}$ with decreasing fat globule size in the presence of SCN or WPC is due to the incorporation of fat into the protein matrix as a consequence of homogenization (Robinson et al., 2006) and to the formation of an increased number of interactions between proteins in the fat globule membranes and in the aqueous phase. This results in aggregates with increased hydrodynamic volume (increased values of $\eta_{0}$ ) and increased number of elastic bonds (increased 
values of $G_{g}$ ). Given that $G_{g}$ reflects the strong chemical bonds, the increase in $G_{g}$ suggests that these bonds are of strong secondary types like hydrogen and electrostatic bonds. According to Lucey and Singh (1998), the bonds that comprise the protein matrix of acid milk gels are strong secondary bonds like hydrogen and electrostatic bonds.
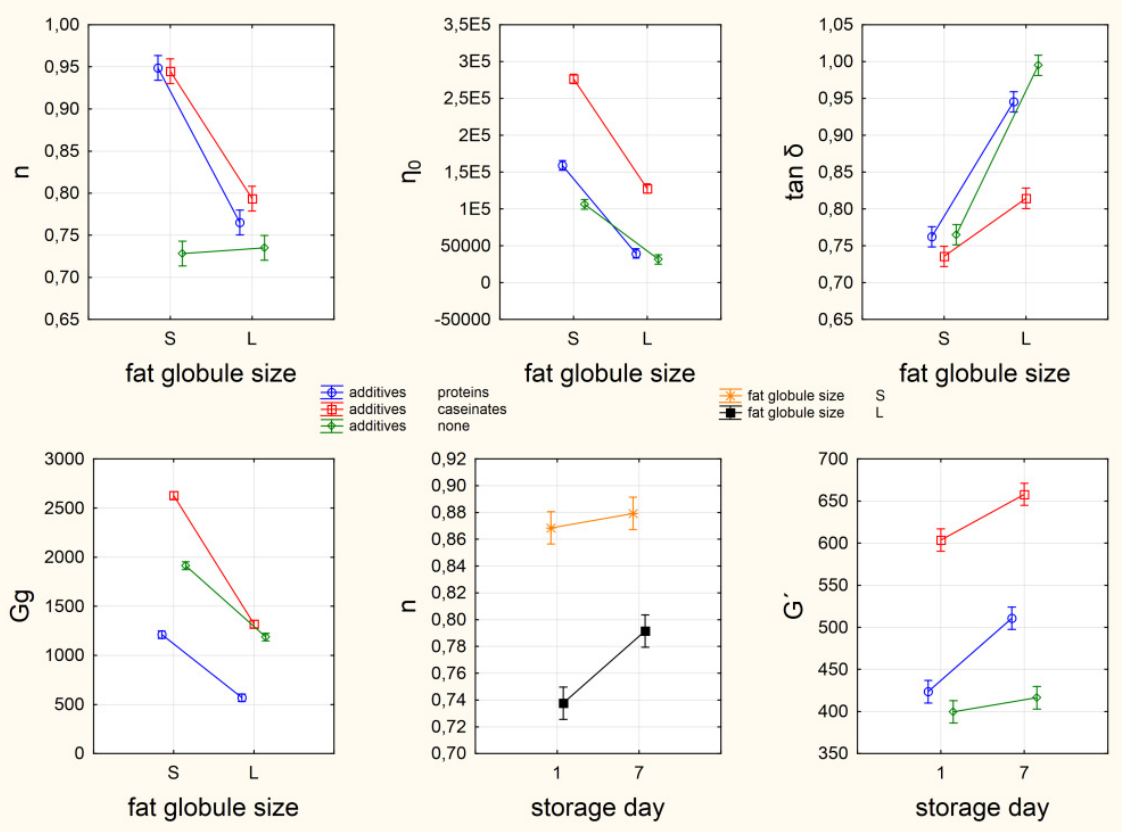

Figure 2. Mean changes of rheological attributes according to particular interaction terms of the three factors.

Vertical bars denote the $95 \%$ confidence intervals of means based on the error mean square of ANOVA.

Abbreviations are as follows, proteins: Whey Proteins Concentrates, S: Small fat globule size, L: Large fat globule size, n: Flow behavior index, G': Elastic modulus, $G_{\mathrm{g}}$ : instantaneous elasticity, $\eta_{0}$ : Newtonian viscosity

An inverse situation holds for $\tan \delta$ where SCN resulted in a lower increasing rate and thus a lower decrease in the elastic character of the samples in products with large globules as compared to WPC or without additives (Figure 2). This is due to the pronounced effect of SCN when compared to WPC. The added caseins interact with the embedded proteins into the fat globule membrane increasing this way the number and strength of the formed bonds and thus the elasticity of the matrix (decreased values of $\tan \delta$ ), even at large fat globule sizes.

Storage time increased the response of $\mathrm{n}$ in yogurts with large fat globules (Figure 2). As it can been seen in Figure 1, during storage the viscosity of the samples is decreased and they tend towards Newtonian behavior. As already explained this is due to the presence of fat, which by the application of high shear rates, bear down on the weak interactions formed between aggregates during storage and break them, thereby reducing the aggregate size and their resistance to flow. However, when fat globule size is reduced fat globules are embedded into the protein matrix and thus their role in structure breakdown during shearing is reduced.

$\mathrm{G}^{\prime}$ increased more rapidly during storage in the presence of SCN and WPC. The addition of caseins or whey proteins enhanced the elastic character of the samples, due to the increased number of protein-protein bonds formed during structure re-formation as storage time is increased. The increase in protein level results in the development of a higher number of protein interactions and protein-protein bonds (Sodini et al., 2004).

The small globule size in combination with no protein addition produced the lowest response of $b$ (Figure 3). In the absence of protein addition, the decrease in fat globule size greatly decreases the yellow color intensity due to the increase in light scattering caused by the increased number of fat globules (Walstra et al., 2006). However, the increasing or decreasing of the yellow color intensity by WPC and SCN, respectively, masks the impact effect of fat globule size. 

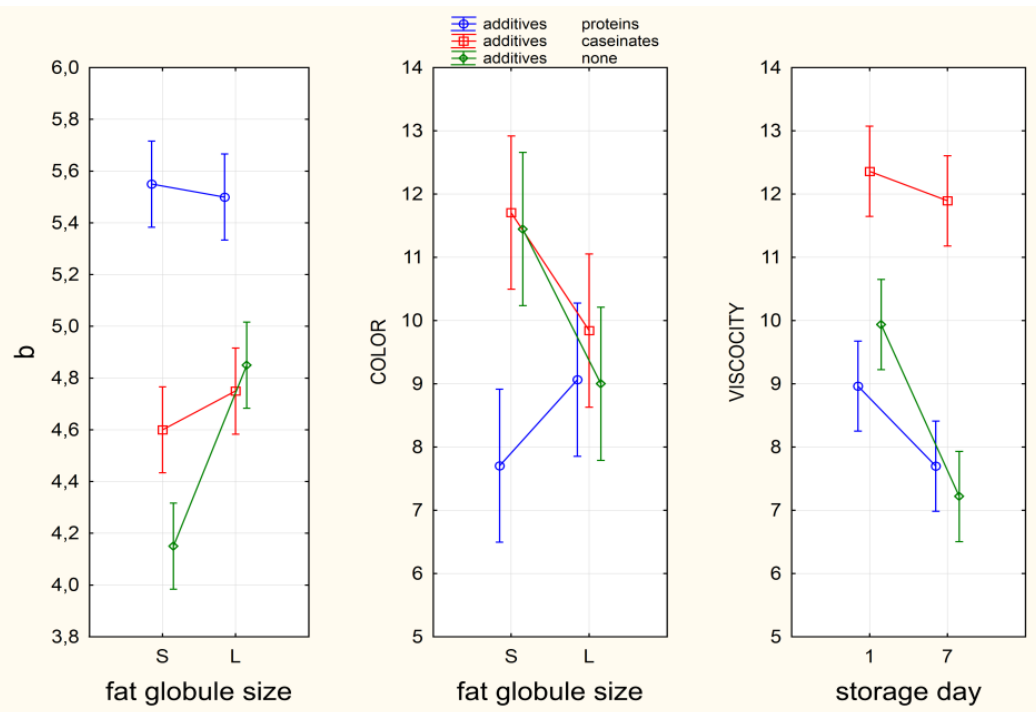

Figure 3. Mean changes of attributes b, objective color and viscosity at particular combined levels among the three factors. Vertical bars denote the $95 \%$ confidence intervals of means calculated from the error mean square of ANOVA. Abbreviations are as follows, proteins: Whey Proteins Concentrates, S: Small fat globule size, L:

Large fat globule size

The decrease in white color intensity was more pronounced with decreasing fat globule size in the presence of WPC (Figure 3). This can be attributed to the fact that whey proteins, due to their interactions with caseins, cover the fat globule surface and reduce the ability of fat globules and casein micelles to scatter light.

Finally, the sensory viscosity declined faster when yogurts were free of additives and conditioned by time. The presence of SCN or WPC increase the number of protein-protein bonds formed (Sodini et al., 2004) during structure re-formation as storage time is increased (Lee \& Lucey, 2006). In the absence of added proteins the number of these bonds is reduced resulting in reduced resistance to flow and thus reduced viscosity.

\subsection{Principal Component Analysis}

To clarify the relationships between the three variable sets of the study (rheological, physicochemical and sensory) the PCA technique was employed. The first two principal axes explain $80.9 \%(55.9+25.0)$ of the total variation (Table 6). Seven attributes with correlation coefficients greater than $|0.700|$ are considered the most responsible for the formation of AXIS 1 and only three for AXIS 2 (white color, odor and b). Correlation coefficients and treatment arrangements are both shown in the biplot of Figure 4. Attributes and factor combinations closely positioned are mutually informative. Thus, $\tan \delta$ increases in yogurts containing large globule size and correlates strongly negatively with, particularly, the bundle formed by the variables a, L, G' and $\eta_{0}$ which are in turn strongly and positively intercorrelated and dominated by small globules in the products in the presence of SCN. Another positively intercorrelated bundle confined by the attributes viscosity, $G_{g}, G_{R}$ and white color, which is indicative of SCN addition, correlates positively with the preceding bundle and negatively with colorimetric b. The latter is important in yogurts enriched with WPC. Odor and n correlate positively with each other showing high responses in the absence of additives (opposite direction towards none-no protein addition). Storage days are located in the centre of the graph indicating minor significant effects. 
Table 6. Correlation coefficients between attributes and principal axes 1 and 2. Values greater than \pm 0.700 are shown in bold

\begin{tabular}{lll}
\hline VARIABLES & AXIS 1 & AXIS 2 \\
\hline$\eta_{0}$ & $\mathbf{- 0 . 9 8 7}$ & -0.069 \\
$\tan \delta$ & $\mathbf{0 . 9 7 9}$ & 0.108 \\
$\mathrm{a}$ & $\mathbf{- 0 . 9 7 3}$ & -0.214 \\
$\mathrm{G}^{\prime}$ & $\mathbf{- 0 . 9 6 3}$ & -0.119 \\
$\mathrm{~L}$ & $\mathbf{- 0 . 9 5 7}$ & -0.178 \\
$\mathrm{VISCOCITY}_{\mathrm{g}_{\mathrm{g}}}$ & $\mathbf{- 0 . 9 0 4}$ & 0.193 \\
$\mathrm{n}$ & $\mathbf{- 0 . 8 5 0}$ & 0.515 \\
$\mathrm{G}_{\mathrm{R}}$ & $\mathbf{- 0 . 7 8 2}$ & -0.618 \\
COLOR & $\mathbf{- 0 . 7 3 1}$ & 0.620 \\
ODOR & -0.649 & $\mathbf{0 . 7 1 3}$ \\
lactic acid & -0.411 & $\mathbf{- 0 . 8 2 2}$ \\
$\mathrm{b}$ & -0.380 & -0.420 \\
FATTINESS & 0.346 & $\mathbf{0 . 9 2 8}$ \\
ACIDITY & -0.346 & -0.588 \\
\hline
\end{tabular}

Abbreviations are as follows, $n$ : Flow behavior index, $G^{\prime}$ : Elastic modulus, $G_{g}$ : instantaneous elasticity, $G_{R}$ : retarded elasticity, $\eta_{0}$ : Newtonian viscosity, and finally $L$, a and $b$ are the three components of color.

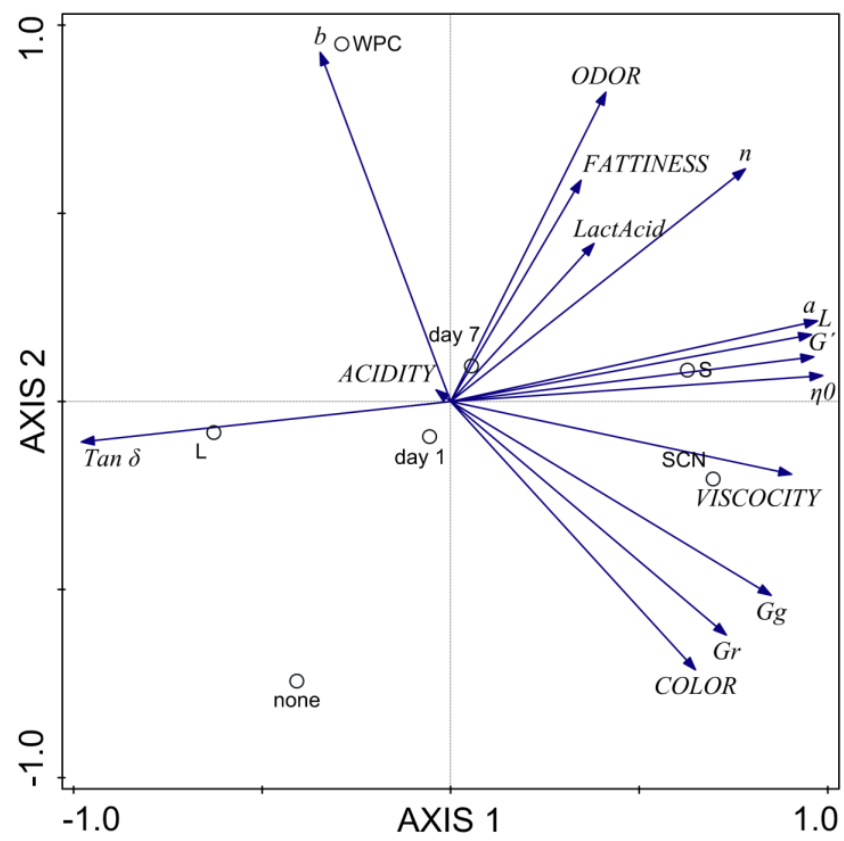

Figure 4. PCA biplot showing the correlations of attributes and the location of treatments. Longer arrows are more important in producing effects, oblique angles show high positive correlation, obtuse angles high negative effect and vertical angles zero correlation. Abbreviations are as follows, WPC: Whey Proteins Concentrates, SCN: Sodium Caseinates, S: Small fat globule size, L: Large fat globule size, n: Flow behavior index, G': Elastic modulus, $\mathrm{G}_{\mathrm{g}}$ : instantaneous elasticity, $\mathrm{G}_{\mathrm{R}}$ : retarded elasticity, $\eta_{0}$ : Newtonian viscosity, LactAcid: Lactic acid concentration, and finally $\mathrm{L}, \mathrm{a}$ and $\mathrm{b}$ are the three components of color 


\section{Conclusion}

- Protein supplementation increased the lactic acid concentration and decreased the green color intensity of yogurt samples. WPC addition caused the yellow color intensity of the samples to increase and the sensory intensity of white color to decrease. The effect of SCN is more pronounced when compared to the effect of WPC, increasing the rheological properties of yogurt samples apart for $\tan \delta$. SCN addition also enhanced the sensory viscosity.

- The decrease in fat globule size caused the brightness of yogurt samples to increase, thereby reducing the green and yellow color intensity. The rheological properties (except tan $\delta$ ) of the samples as well as the sensory fattiness also increased with decreasing fat globule size.

- Storage time increased the lactic acid concentration, the sensory acidity and the rheological properties of yogurt samples apart from $\tan \delta$ and apparent viscosity.

- Caseinates, in yogurts with small fat globules, produced higher levels of $G^{\prime}$ and $\eta_{0}$ and the color parameters a and $\mathrm{L}$ whereas in yogurts with large fat globule size, they markedly reduced $\tan \delta$.

- Storage time increased the response of $\mathrm{n}$ in yogurts with large fat globules and more rapidly the response of $\mathrm{G}^{\prime}$ in the presence of SCN and WPC. The sensory viscosity reduced the most during storage in yogurt samples with no protein addition.

- The small globule size in combination with no protein addition produced the lowest response of $b$ and when WPC was present the lowest white color intensity.

- The most important parameters affecting rheological properties, sensory viscosity and color parameters a and $\mathrm{L}$ of yogurt samples are SCN and fat globule size.

\section{Acknowledgements}

The authors wish to thanks Mr Andrea Andreadi for the supply of the buffalo milk, Mr Kleona Tsakmakidi (Hellenic Protein S.A.) for the supply of the SCN and WPC as well as Jonathan Rhoades for revising the English version of the manuscript.

\section{References}

Agnihotri, M. K., \& Prasad, V. S. S. (1993). Biochemistry and processing of goat milk and milk products. Small Ruminant Research, 12, 151-170. http://dx.doi.org/10.1016/0921-4488(93)90080-2

Ahmad, S., Gaucher, I., Rousseau, F., Beaucher, E., Piot, M., Gronget, J. F., \& Gaucheron, F. (2008). Effects of acidification on physico-chemical characteristics of buffalo milk: A comparison with cows' milk. Food Chemistry, 106, 11-17. http://dx.doi.org/10.1016/j.foodchem.2007.04.021

Amatayakul, T., Halmos, A. L., Sherkat, F., \& Shah, N. P. (2006) Physical characteristics of yogurts made using exopolysaccharide-producing starter cultures and varying casein to whey protein ratios. International Dairy Journal, 16, 40-51. http://dx.doi.org/10.1016/j.idairyj.2005.01.004

AOAC. (2002). Official Methods of Analysis, (17th Ed.). Gaithersburg, Maryland: Association of Official Analytical Chemists.

Cho, Y. H., Lucey, J. A., \& Singh, H. (1999). Rheological properties of acid gels as affected by the nature of the fat globule surface material and heat treatment of milk. International Dairy Journal, 9, 537-545. http://dx.doi.org/10.1016/S0958-6946(99)00123-5

Cochran, W. G., \& Cox, G. M. (1957). Experimental designs (2nd ed.). New York: Wiley.

Dimitreli, G., \& Thomareis, A. S. (2004). Effect of temperature and chemical composition on processed cheese apparent viscosity. Journal of Food Engineering, 64, 265-271. http://dx.doi.org/10.1016/j.jfoodeng.2008.10.008

Fox, P. F., \& McSweeney, P. L. H. (1998). Dairy chemistry and biochemistry. London, Weinheim, New York, Tokyo, Melbourne, Madras: Blackie Academic \& Professional.

Hanif, M. S., Zahoor, T., Iqbal, Z., Ihsan-ul-haq, \& Arif, A. M. (2012). Effect of storage on the rheological and sensory characteristics of cow and buffalo milk yogurt. Pakistan Journal of Food Sciences, 22(2), 61-70.

ISO. (1976). Milk-Determinationof fat content-(Boutyrometric routine method). ISO Standard 2446. Geneva: International Standards Organization.

Khedkar, C. D., Khedkar, G. D., Patil, M. R., \& Kalyankar, S. D. (2003). Encyclopedia of Food Sciences \& nutrition (2nd $\quad$ ed.). (705-709). Maryland: Academic Press. http://dx.doi.org/10.1016/B0-12-227055-X/00134-6 
Lee, W.-J., \& Lucey, J. A. (2006). Impact of gelation conditions and structural breakdown on the physical and sensory properties of stirred yogurts. Journal of Dairy Science, 89, 2374-2385. http://dx.doi.org/10.3168/jds.S0022-0302(06)72310-4

Lucey, J. A. (2004). Cultured dairy products: an overview of their gelation and texture properties. International Journal of Dairy Technology, 57, 77-84. http://dx.doi.org/10.1111/j.1471-0307.2004.00142.x

Lucey, J. A., \& Singh, H. (1998). Formation and physical properties of acid milk gels: a review. Food Research International, 30, 529-542. http://dx.doi.org/10.1016/S0963-9969(98)00015-5

Lucey, J. A., Munro, P. A., \& Singh, H. (1998). Rheological properties and microstructure of acid milk gels as affected by fat content and heat treatment. Journal of Food Science, 63, 660-664. http://dx.doi.org/10.1111/j.1365-2621.1998.tb15807.x

Masud, T., Khalid, S., Maqsood, S., \& Bilal, A. (2010). Preservation of raw buffalo's milk by the activation of lactoperoxidase system and its effect on yogurt preparation. Journal of Food Processing and Preservation, 34, 241-254. http://dx.doi.org/10.1111/j.1745-4549.2008.00337.x

Munoz, A., \& Civille, G. V. (1998). Universal product and attribute specific scaling and development of specific lexicons in descriptive analysis. Journal of Sensory Studies, 13, 57-75. http://dx.doi.org/10.1111/j.1745-459X.1998.tb00075.x

Park, Y. W., Juárez, M., Ramos M. \& Haenlein G. F. W. (2007). Physico-chemical characteristics of goat and sheep milk. Small Ruminant Research, 68, 88-113. http://dx.doi.org/10.1016/j.smallrumres.2006.09.013

Petridis, D., Dimitreli, G., Chrysalidou, S., \& Akakiadou, P. (2013). Optimization of the rheological and sensory properties of stirred yogurt as affected by chemical composition and heat treatment of buffalo milk. Journal of Food Research, 2, 55-70. http://dx.doi.org/10.5539/jfr.v2n6p55

Remeuf, F., Mohammed, S., Sodini, I., \& Tissier, J. P. (2003). Preliminary observations on the effects of milk fortification and heating on microstructure and physical properties of stirred yogurt. International Dairy Journal, 13, 773-782. http://dx.doi.org/10.1016/S0958-6946(03)00092-X

Robinson, R. K., Lucey, J. A., \& Tamine, A. Y. (2006). Manufacture of yogurt. In A. Y. Tamine (Ed.), Fermented milks (pp. 53-75). Oxford, Iowa, Victoria: Blackwell Science Ltd. http://dx.doi.org/10.1002/9780470995501.ch3

Salaün, F., Mietton, B., \& Gaucheron, F. (2005). Buffering capacity of dairy products. International Dairy Journal, 15, 95-109. http://dx.doi.org/10.1016/j.idairyj.2004.06.007

Serra, M., Trujillo, A. J., Guamis, B., \& Ferragut, V. (2009). Evaluation of physical properties during storage of set and stirred yogurts made from ultra-high pressure homogenization-treated milk. Food Hydrocolloids, 23, 82-91. http://dx.doi.org/10.1016/j.foodhyd.2007.11.015

Sharma, S. (1996). Applied multivariate techniques. New York: John Wiley and Sons.

Simanca, M. M., Andrade, R. D., \& Arteage, M. R. (2013). Effect of bran wheat on the physico-chemical and sensory properties of buffalo mil yogurt. Información Tecnológica, 24(1), 79-86. http://dx.doi.org/10.4067/S0718-07642013000100010

Sodini, I., Remeuf, F., Haddad, S., \& Corrieu, G. (2004). The relative effect of milk base starter culture and process on yogurt texture: A review. Critical Reviews in Food Science and Nutrition, 44, 113-137. http://dx.doi.org/10.1030/10408690490424793

Tamine, A. Y., \& Robinson, R. K. (2007). Tamine and Robinson's yogurt. Science and technology (3rd ed.). Boca Raton, Boston, New York, Washington, DC: CRC Press.

Walstra, P., Wouters, J. T. M., \& Geurts, T. J. (2006). Dairy Science and Technology (2nd ed.). Boca Raton: Taylor \& Francis, CRC Press.

Wu, H., Hulbert, G. J., \& Mount, J. R. (2001). Effects of ultrasound on milk homogenization and fermentation with yogurt starter. Innovative Food Science \& Emerging Technologies, 1, 211-218. http://dx.doi.org/10.1016/S1466-8564(00)00020-5

\section{Copyrights}

Copyright for this article is retained by the author(s), with first publication rights granted to the journal.

This is an open-access article distributed under the terms and conditions of the Creative Commons Attribution license (http://creativecommons.org/licenses/by/3.0/). 